\title{
Cerebral Hemodynamic Evaluation of Parent Artery Occlusion for Giant Intracranial Aneurysm in Patients who Tolerated Balloon Test Occlusion: Two Case Reports
}

\author{
Balon Oklüzyon Testini Tolere Eden ve Dev Intrakranial \\ Anevrizması Olan Hastalarda Komşu Arter Oklüzyonunda Serebral \\ Hemodinamiklerin Değerlendirilmesi: İki Olgu Sunumu
}

\author{
Xiao Qing CHENG*, Chang Sheng ZHOU,, Qian CHEN, Guang Ming LU \\ Nanjing University, Clinical School of Medical College, Jinling Hospital, Department of Medical Imaging, Nanjing, \\ Jiangsu Province 210002, China \\ ${ }^{*} C H E N G$ and $\mathrm{ZHOU}$ contributed equally to the manuscript.
}

Corresponding Author: Guang Ming LU / E-mail: cjr.luguangming@vip.163.com

\begin{abstract}
Parent artery occlusion is an effective treatment for giant intracranial aneurysms that cannot be clipped directly by surgery in patients who tolerate balloon test occlusion. However, concern remains that impaired hemodynamics after parent artery occlusion may cause delayed ischemic events in the ipsilateral hemisphere. We used computed tomography perfusion studies to evaluate the cerebral hemodynamics before and after parent artery occlusion in two patients with giant intracranial aneurysms who tolerated balloon test occlusion. In the first case, significant vortex flow in the aneurysm cavity prevented distal vascular engorgement and caused severe ischemic changes. After parent artery occlusion, the vortex flow was eliminated, circle of Willis compensatory flow was restored, and cerebral hemodynamics were significantly improved. In the second case, cerebral hemodynamics were normal on preoperative computed tomography perfusion. After parent artery occlusion, the time-to-peak was prolonged in the cerebral hemisphere on the occluded side compared with the contralateral hemisphere.
\end{abstract}

KEYWORDS: Aneurysm, Balloon test occlusion, Parent artery occlusion, Perfusion

öz

Balon oklüzyon testini tolere eden ve direkt olarak cerrahi yolla kliplenemeyecek dev intrakranial anevrizması olan hastalarda komşu arter oklüzyonu efektif bir tedavi yöntemidir. Ancak komşu arter oklüzyonundan sonra bozulmuş olan hemodinamikler ileri dönemde aynı taraftaki hemisferde iskemik olaylara neden olabilir. Biz balon oklüzyonu testini tolere eden ve dev intrakranial anevrizması olan 2 hastada komşu arter oklüzyonundan önce ve sonra serebral hemodinamikleri değerlendirmek amacıyla bilgisayarlı tomografi perfüzyon çalışmalarını kullandık. Birinci olguda anevrizma kavitesindeki belirgin girdap akımı distal vasküler geçişi engellemiş ve ciddi iskemik değişikliklere neden olmuştur. Komşu arter oklüzyonundan sonra girdap akımı düzelmiş, Willis poligonunda kompensatuar akım sağlanmış ve serebral hemodinamikler belirgin şekilde düzelmiştir. İkinci olguda ise, preoperatif bilgisayarlı tomografi perfüzyon çalışmasında serebral hemodinamikler normal idi. Komşu arter oklüzyonundan sonra, tıkanan tarafta serebral hemisferde kan akımının zirve noktaya erişim süresi karşı hemisfere gore uzamıştır.

ANAHTAR SÖZCÜKLER: Anevrizma, Balon oklüzyon testi, Komşu arter oklüzyonu, Perfüzyon

\section{INTRODUCTION}

A giant intracranial aneurysm $(\mathrm{GIA})$ is defined as an aneurysm larger than $25 \mathrm{~mm}$ in diameter. If untreated, GIAs have a 5 -year mortality rate of more than $80 \%$ (7). A long-term follow-up study has shown parent artery occlusion (PAO) to be a mainstay of treatment for GIAs that cannot be clipped directly by surgery (2). However, PAO can lead to insufficient cerebral blood perfusion and result in ischemic stroke due to incomplete compensation by the collateral circulation.
The indications and selection of grafts for concomitant revascularization are determined by the patient's tolerance of balloon test occlusion (BTO). However, even after successful BTO, delayed ischemic complications may occur in $4-15 \%$ of cases (5). Combined hemodynamic evaluation can identify patients at risk of developing cerebral ischemia after PAO. In the cases reported here, we used computed tomography perfusion (PCT) studies to evaluate cerebral hemodynamics before and after PAO in two patients with GIA who tolerated BTO. 


\section{CASE REPORTS}

Case 1:

A58-year-old woman with complaints of dizziness and right eye diplopia that had progressively worsened over 3 months was admitted to the hospital in August 2013. Cerebral angiography showed a GIA in the right carotid ophthalmic artery (Figure $1 \mathrm{~A})$ and significant vortex formation in the aneurysm cavity, which prevented distal vascular engorgement. PCT revealed severely impaired cerebral hemodynamics in the right hemisphere of the brain. Compared with the left hemisphere, the right hemisphere showed decreased cerebral blood flow (CBF) and cerebral blood volume (CBV), and the time-topeak (TTP) was significantly extended (Figures 1D-F). The patient tolerated BTO, and PAO was performed. Postoperative angiography showed that the parent artery was completely

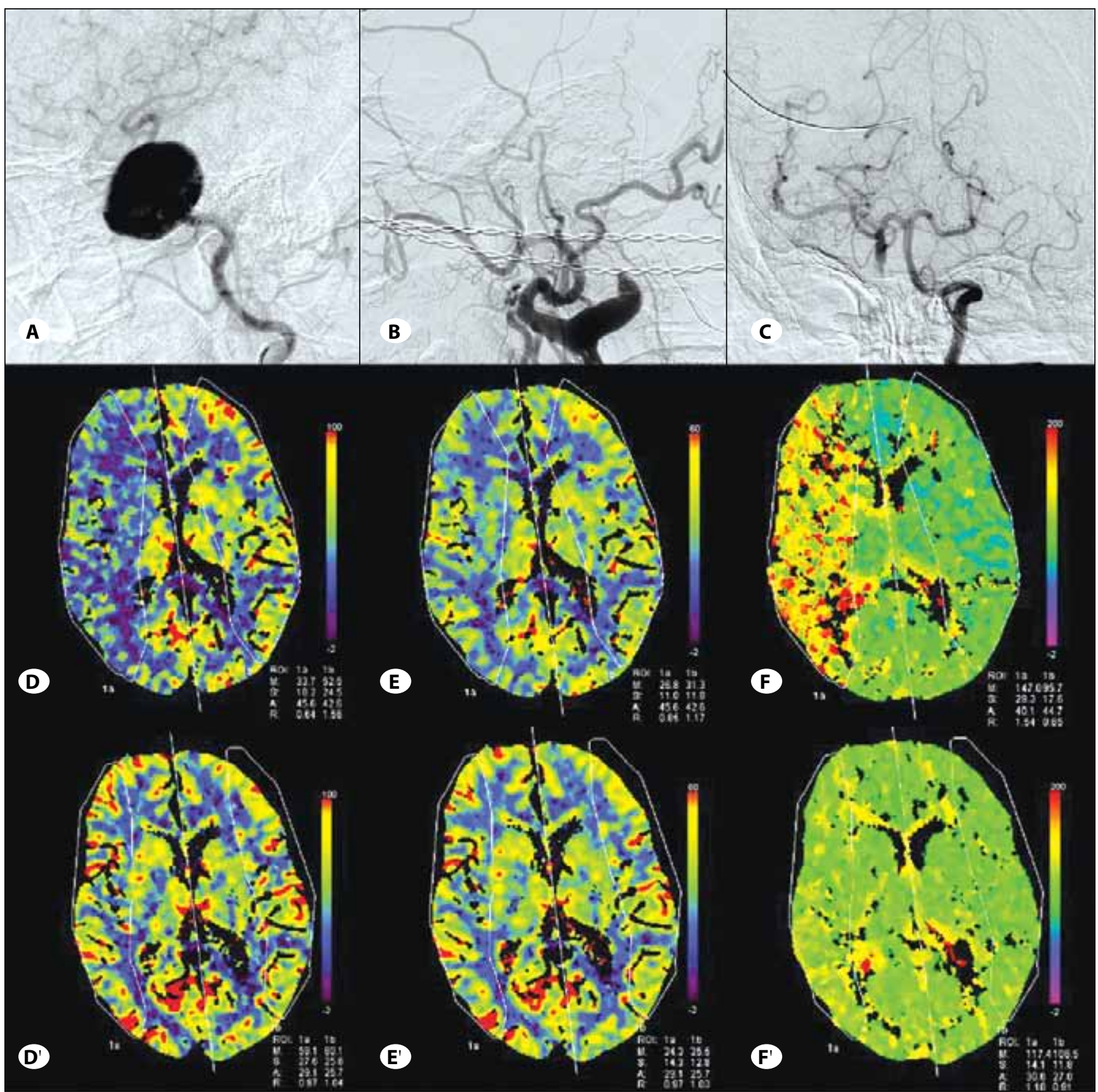

Figure 1: Preoperative and postoperative PCT images of a GIA at ophthalmic segments of the right internal carotid artery. Preoperative angiography demonstrated a GIA at ophthalmic segments of the right internal carotid artery (A). Postoperative angiography revealed parent artery occlusion and (B) patent collateral vessels via the posterior communicating artery (C). Preoperative PCT showed decreased cerebral blood flow (D). CBV was decreased on preoperative PCT (E). TTP was increased in the right hemisphere preoperatively (F). Postoperative follow-up PCT showed improvement in cerebral hemodynamics ( $\left.\mathbf{D}^{\prime}-\mathbf{F}^{\prime}\right)$. 
occluded and the aneurysm had not refilled, and good levels of compensatory cross-circulation were observed (Figures 1B, C). PCT on postoperative day 2 showed that CBF perfusion was significantly recovered. TTP was significantly reduced and the CBF and CBV of the right cerebral hemisphere were significantly increased and symmetric with the left hemisphere (Figures 1 $D^{\prime}-F^{\prime}$ ). At the 1-year follow-up, the patient had no cerebral ischemic symptoms and her diplopia had completely resolved.

\section{Case 2:}

A 36-year-old man presented with right tonsillar enlargement, leading to the diagnosis of a giant right carotid cavernous artery aneurysm on computed tomography angiography

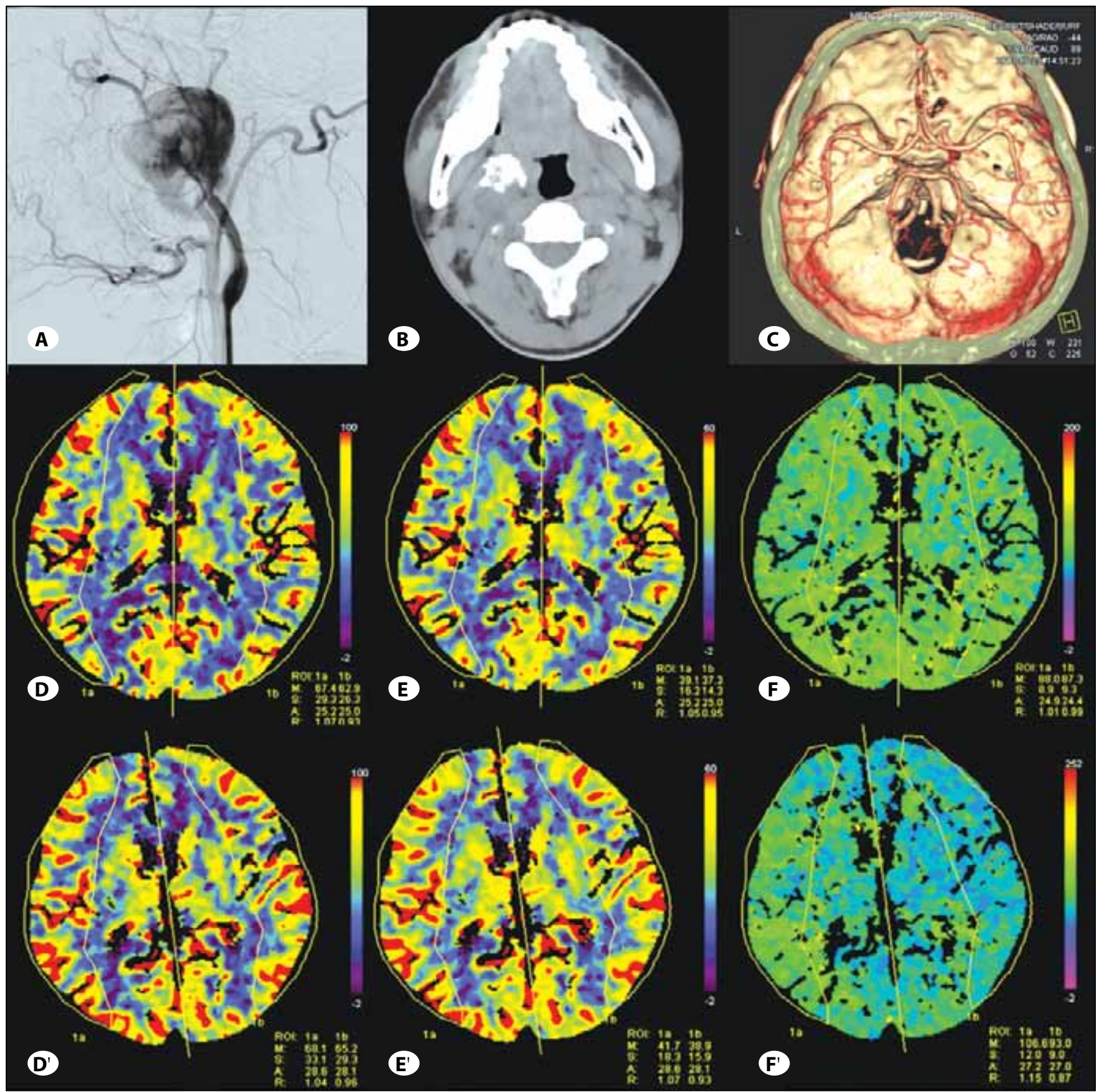

Figure 2: Preoperative and postoperative PCT images of a GIA at the cavernous segment of the right internal carotid artery. Preoperative angiography demonstrated a GIA at the cavernous segment of the right internal carotid artery (A). Axial unenhanced CT showed irregular calcification on the wall of the aneurysm (B). Postoperative CTA observed good compensatory cross-circulation (C). Preoperative PCT showed normal cerebral hemodynamics (D-F). Postoperative follow-up PCT showed that CBF and CBV were not significantly altered ( $\left.\mathbf{D}^{\prime}, \mathbf{E}^{\prime}\right)$. TTP was extended in the right hemisphere postoperatively (F'). 
(CTA) that was subsequently confirmed on angiography in June 2013 (Figure 2A). Axial unenhanced CT showed irregular calcification on the wall of the aneurysm (Figure 2B). Preoperative PCT showed normal cerebral hemodynamics (Figures 2D-F). The patient tolerated BTO, and PAO was performed. Postoperative CTA showed that the parent artery was completely occluded and the aneurysm had not refilled, and good compensatory cross-circulation was observed (Figure 2C). PCT on postoperative day 6 showed an extended TTP in the right hemisphere compared with the left hemisphere (Figure $2 \mathrm{~F}^{\prime}$ ), but $\mathrm{CBF}$ and $\mathrm{CBV}$ were not significantly altered (Figures 2D', $E^{\prime}$ ). At the 3-month follow-up, the patient had no significant cerebral ischemic symptoms.

\section{DISCUSSION}

PAO is a safe, effective treatment for GIAs in the cervical, cavernous sinus or petrous internal carotid arteries that are not amenable to surgical clipping due to having a spindle shape, a wide neck or no neck (2). The aim of aneurysm surgery is to eliminate the compression of surrounding vital structures, prevent the aneurysm from rupturing and maintain a sufficient cerebral blood supply. However, PAO may lead to insufficient CBF and result in ischemic stroke due to incomplete compensation by the collateral circulation. BTO is required to determine whether a patient will tolerate PAO and the necessity of revascularization. However, despite tolerating BTO, a significant percentage of patients still suffer delayed ischemic events (5). Therefore, for PAO, the evaluation of cerebral hemodynamics is needed to identify patients at risk for ischemic infarction.

Cerebral hemodynamics may be assessed using single-photon emission computed tomography (CT), xenon-enhanced CT $(\mathrm{XeCT})$ or perfusion-weighted magnetic resonance imaging (MRI) during PAO $(3,4,8)$. Field et al. (3) evaluated outcomes in patients with symptomatic cavernous sinus aneurysms who had normal clinical BTO and underwent PAO. BTO combined with quantitative $\mathrm{CBF}$ analysis by $\mathrm{XeCT}$ showed that patients in whom cortical CBF was reduced to below $30 \mathrm{~mL} / 100 \mathrm{~g} / \mathrm{min}$ were at moderate risk for post-occlusion ischemic infarction and those with cortical CBF greater than $30 \mathrm{~mL} / 100 \mathrm{~g} /$ min were at low risk. Gevers et al. (4) used MRI arterial spin labeling to assess post-PAO hemodynamics in GIA patients who had tolerated BTO. The results of this study show that there was no significant difference in CBF between ipsilateral and contralateral hemispheres, although timing parameters were significantly prolonged on the side of the occlusion.

PCT is now mainly used to predict the presence of an ischemic penumbra following acute cerebral infarction and to evaluate cerebrovascular reserve capacity in chronic ischemia $(1,6$, 8). In the present cases, the two patients exhibited different patterns of hemodynamic change before and after PAO. In the first case, significant vortex flow in the aneurysm cavity prevented distal vascular engorgement and caused severe ischemic changes. After PAO, the vortex flow was eliminated, circle of Willis compensation was restored and the cerebral hemodynamics were significantly improved. Postoperative PCT confirmed the improvement in cerebral hemodynamics, indicating that the PAO was effective in improving the cerebral ischemia caused by this type of GIA, which has not been reported previously.

In the second case, there was no significant difference in CBF or CBV between the ipsilateral and contralateral hemispheres to internal carotid artery occlusion after PAO; however, TTP was prolonged on the side of the occlusion. The unchanged $\mathrm{CBF}$ and $\mathrm{CBV}$ suggest that compensatory mechanisms were activated to maintain adequate blood flow and prevent infarction. Prolonged TTP in the ipsilateral hemisphere could be due to longer perfusion distances and smaller vessel diameters of the collateral pathways that reduce the flow rate. Therefore, in agreement with previous studies (4), TTP is a sensitive and useful indicator of hemodynamic changes during PAO.

In conclusion; our cases suggest that PCT can demonstrate preoperative and postoperative changes of cerebral hemodynamics after PAO for GIA in patients who tolerated BTO. Furthermore, TTP is a sensitive and useful indicator of hemodynamic changes during PAO.

\section{ACKNOWLEDGMENTS}

Xiao Qing CHENG received a research grant from the Natural Scientific Foundation of China (81201072)

\section{REFERENCES}

1. Cheng, XQ, Tian, JM, Zuo, CJ, Liu, J, Zhang, Q, Lu, G $\mathrm{M}$ : Quantitative perfusion computed tomography measurements of cerebral hemodynamics: Correlation with digital subtraction angiography identified primary and secondary cerebral collaterals in internal carotid artery occlusive disease. Eur J Radiol 81:1224-1230, 2012

2. Clarençon F, Bonneville F, Boch AL, Lejean L, Biondi A: Parent artery occlusion is not obsolete in giant aneurysms of the ICA. Experience with very-long-term follow-up. Neuroradiology 53:973-982, 2011

3. Field $M$, Jungreis $C A$, Chengelis $N$, Kromer $H$, Kirby $L$, Yonas $\mathrm{H}$ : Symptomatic cavernous sinus aneurysms: Management and outcome after carotid occlusion and selective cerebral revascularization. Am J Neuroradiol 24:1200-1207, 2003

4. Gevers S, Heijtel D, Ferns SP, van Ooij P, van Rooij WJ, van Osch MJ, Majoie CB: Cerebral perfusion long term after therapeutic occlusion of the internal carotid artery in patients who tolerated angiographic balloon test occlusion. Am J Neuroradiol 33:329-335, 2012

5. Gonzalez NR, Duckwiler G, Jahan R, Murayama Y, Viñuela F: Challenges in the endovascular treatment of giant intracranial aneurysms. Neurosurgery 59:113-124, 2006

6. Jain R, Hoeffner EG, Deveikis JP, Harrigan MR, Thompson BG, Mukherji SK: Carotid perfusion CT with balloon occlusion and acetazolamide challenge test: Feasibility. Radiology 231:906913,2004

7. Scozzafava J, Sutherland G: Giant intracranial aneurysm. Can Med Assoc J 183:E604, 2011

8. Shimizu H, Matsumoto Y, Tominaga T: Parent artery occlusion with bypass surgery for the treatment of internal carotid artery aneurysms: Clinical and hemodynamic results. Clin Neurol Neurosurg 112:32-39, 2010 